\title{
Assessment of Sympathetic Function Test in Breast Cancer Patients after Chemotherapy Treatment (Anthracycline Group of Drug Particular Doxorubicin)
}

\author{
Ms. Islam Khan ${ }^{1 *}$, Dr. Raghuveer Choudhary ${ }^{2}$, Dr. Kamla Choudhary ${ }^{3}$, Dr. Vihan Chawdhary ${ }^{4}$, Ms. Nikita Jain ${ }^{5}$
}

${ }^{1} \mathrm{PhD}$ Scholar, Department of Physiology, Dr. S. N. Medical College, Jodhpur, Rajasthan, India

${ }^{2}$ Professor \& Head, Department of Physiology, Dr. S. N. Medical College, Jodhpur, Rajasthan, India

${ }^{3}$ Assistant Professor, Department of Physiology, Dr. S. N. Medical College, Jodhpur, Rajasthan, India

${ }^{4}$ Assistant Professor, Department of Biochemistry, Dr. S. N. Medical College, Jodhpur, Rajasthan, India

${ }^{5}$ Tutor, Banas Medical College \&Research Institute, Palampur, India

DOI: $10.36347 /$ sjams.2020.v08i06.005

| Received: 20.05.2020 | Accepted: 03.06.2020 | Published: 10.06.2020

*Corresponding author: Ms. Islam Khan

Abstract

Original Research Article

Breast cancer, one of the most common malignancies affecting woman worldwide. Treatment of breast cancer by Anthracycline group of drug which are the most effective anticancer treatments ever develops. However, cardio toxicity is a well-recognized side effect of anthracycline treatment and can cause heart failure. The aim of the study was to Assessment of sympathetic function test in breast cancer patients after chemotherapy treatment. We enroll 125 symptomatic breast cancer patients (Before and after chemotherapy treatment) who treated with anthracycline group of drug. To assess the Sympathetic functions CANWin device was used. The result showed that $\Delta$ SBP after standing is significantly increased while $\triangle \mathrm{DBP}$ after SHP (SUSTAIN HAND GRIP TEST) significantly decreased in breast cancer patients after chemotherapy (Anthracycline) treatment.

Keywords: Sympathetic Breast Cancer.

Copyright @ 2020: This is an open-access article distributed under the terms of the Creative Commons Attribution license which permits unrestricted use, distribution, and reproduction in any medium for non-commercial use (NonCommercial, or CC-BY-NC) provided the original author and source are credited.

\section{INTRODUCTION}

The word Cancer is a latin word for " $C R A B$ ". Cancer is a terrifying illness with a heterogeneous group of disease due to uncontrolled growth of abnormal cells which can extend in any tissue or organ of body and can cause damage to normal tissue as they do not die and continuously grow and divide in disorderly fashion.

The cancerous cells frequently break free from the tumor site and enter the bloodstream, spreading the disease to other organs and this process is called metastasis [1]. The most common types of cancers with highest rate of mortality are the cancers of lung, stomach, liver, colorectal and esophagus among men and the breast, lung, stomach, colorectal and cervical cancers among women. Breast cancer, one of the common malignancies affecting women worldwide [2].

Risk factors for developing breast cancer include female sex, obesity, and lack of physical exercise, drinking alcohol, hormone replacement therapy during menopause, ionizing radiation, and early age at first menstruation having children late or not at all, older age and family history. The main factors that influence your breast cancer risk are being a woman and getting older.

Treatment of breast cancer by chemical medications taken either orally or intravenously is a common method of treating breast cancer which has either metastasized or is threatening to metastasize to the lymph nodes or other body areas. Breast cancer chemotherapy refers to the use of specific agents which are toxic (cytotoxins) which kill the cells, essentially by poising them.

Anthracyclines (or anthracyclines antibiotics) are a class of drugs used in cancer chemotherapy [3]. The anthracyclines are among the most effective anticancer treatments ever develops and are effective against more types of cancer than any other class of chemotherapeutic agents. However, cardio toxicity is a well-recognized side effect of anthracycline treatment and can cause heart failure in some patients. Cardiotoxicity can become clinically overt shortly after the commencement of anthracycline treatment but may also manifest many year later [4]. Loss of normal autonomic regulation of the cardiovascular system 
associated with both excessive sympathetic nervous system (SNS) activation and a reduced ability of the parasympathetic nervous system (PNS) to deactivate appropriately, results Autonomic Dysfunction. Autonomic dysfunction can result in increased heart rate, atrio-ventricular node conduction, and left ventricular contractility Lakoski et al. [5] propose the potential mechanism associated with both autonomic dysfunction and increased cardiovascular disease risk in BC patients [6]. Since, studies related to cardiotoxicity in breast cancer treated with anthracycline group of drugs are unfortunately less so the present study was aimed to, investigate cardio toxicity in breast cancer patients, treated with anthracycline group of drugs by assessment of the autonomic (Sympathetic) functions in CANWin device. This device is PC windows based Cardiac Autonomic Neuropathy (CAN) Analysis System with interpretation.

\section{Material ANd Methods}

The present study was carried out in Department of Physiology, in consort with Department of Radiotherapy, Dr. S.N. Medical College, Jodhpur, and Rajasthan. We enrolled symptomatic 250 female breast cancer [Before \& After treatment (Chemotherapy with Anthracycline group of drug)] patients with age ranging 20-70 year age group. Before inclusion into the study all ethical consideration for the subjects were taken in account. An informed written consent was obtained from each subject.

All Subjects tested under similar laboratory conditions and allowed to acclimatize themselves to experimental and environmental conditions for one hour so that they relaxed and rested, as anxiety and stress can affect autonomic functions. The procedure of each and every test explained to the Cases before conducting the tests.

Detail history including personal history, drug history and past medical history taken and recorded in a prefixed questionnaire.

\section{InCLUSION CRITERIA}

- 25-70 year aged diagnosed breast cancer patients.

- Consent will be taken from all the participants before conducting the study.

\section{EXCLUSION CRITERIA}

- Any other chronic diseases affecting autonomic functions and cardiac functions.

- Drugs affecting the autonomic functions and cardiac functions.

- Non-cooperative subjects and not able to communicate.

The anthropometric data i.e. Height (ht), Weight (Wt) to calculate Body Mass Index (BMI) was taken before and after chemotherapy in breast cancer patients.

To assess the autonomic (Sympathetic) functions CANWin device was used. This device is PC windows based Cardiac Autonomic Neuropathy (CAN) Analysis System with interpretation. It is used to analyses;

\section{Procedure for Measurement [Wt (kg) / Ht (m2)] \\ Sympathetic Parameters- \\ - BP response to standing \\ - BP response to sustained handgrip}

Body Mass Index (BMI) - was calculated by dividing the weight taken in $\mathrm{kg}$ by the square of height taken in meters. It was calculated by Quetlet's index

\section{STATiSTiCAl AnAlysis}

Mean and standard deviation of all measured parameters of all subjects were calculated by Microsoft Excel. The data were computed by student $t$ test in 'Open Epi' software. The $\mathrm{p}<0.05$ was considered as statistically significant.

\section{RESULTS}

All the subjects in both (pre \& post treatment) the group were subjected to record various parameters including anthropometric measurements, Sympathetic function tests in breast cancer patients treated with Anthracycline group of drug. Table -1 shows the comparison of BMI. ( $\mathrm{Kg} / \mathrm{m} 2)$ parameters between the breast cancer patients before and after chemotherapy treatment. The result showed that BMI is highly significantly $(\mathrm{p}<0.000)$ decreased in breast cancer patients after chemotherapy (Anthracycline group of drug) treatment.

Table-1: Anthropometric measurement in breast cancer patients before and after chemotherapy treatment

\begin{tabular}{|c|c|c|c|}
\hline Parameters & $\begin{array}{c}\text { Before } \\
\text { chemotherapy } \\
(\text { Mean } \pm \text { SD })\end{array}$ & $\begin{array}{l}\text { After chemotherapy } \\
\quad(\text { Mean } \pm \text { SD })\end{array}$ & $\begin{array}{c}\text { Students - t test } \\
\text { p- value }\end{array}$ \\
\hline Height (cm) & $175 \pm 136.02$ & $175 \pm 136.02$ & \multirow{3}{*}{$\begin{array}{c}\text { (BMI) } \\
0.0000001(\mathrm{HS})\end{array}$} \\
\hline Weight (Kg) & $68.90 \pm 9.98$ & $65.90 \pm 65.82$ & \\
\hline BMI $\left(\mathrm{Kg} / \mathrm{m}^{2}\right)$ & $0.013 \pm .0147$ & $0.071 \pm 0.073$ & \\
\hline
\end{tabular}

All value expressed as mean \& SD; *p value $>0.05(\mathrm{NS}) * *$ p value $<0.05(\mathrm{~S}) * * * \mathrm{p}$ value $<0.01$ (HS) 
Table-2: Comparison of sympathetic autonomic function test in breast cancer patients before after chemotherapy treatment

\begin{tabular}{|c|c|c|c|c|}
\hline $\begin{array}{c}\text { Sympathetic } \\
\text { tests }\end{array}$ & Parameters & $\begin{array}{c}\text { Before } \\
\text { Chemotherapy } \\
(\text { Mean } \pm \text { SD) }\end{array}$ & $\begin{array}{c}\text { After } \\
\text { Chemotherapy } \\
\text { (Mean } \pm \text { SD) }\end{array}$ & $\begin{array}{c}\text { Students }- \text { test } \\
\text { p- value }\end{array}$ \\
\hline $\begin{array}{c}\text { Lying To } \\
\text { Standing }\end{array}$ & $\Delta$ SBP $(\mathrm{mmHg})$ & $6.14 \pm 6.10$ & $14.46 \pm 8.04$ & $<0.002(\mathrm{~S})$ \\
\hline $\begin{array}{c}\text { Sustain Hand } \\
\text { Grip Test }\end{array}$ & $\Delta \mathrm{DBP}(\mathrm{mmHg})$ & $12.56 \pm 3.511$ & $4.73 \pm 2.56$ & $0.0004(\mathrm{~S})$ \\
\hline
\end{tabular}

All value expressed as mean \& SD; *p value $>0.05(\mathrm{NS}) * * \mathrm{p}$ value $<0.05(\mathrm{~S}) * * * \mathrm{p}$ value $<0.01(\mathrm{HS})$

Table No. 2 showing the comparison of sympathetic test (Autonomic function test) in between breast cancer patients before and after chemotherapy treatment. The result showed that $\triangle \mathrm{SBP}$ after standing is significantly increased while $\triangle \mathrm{DBP}$ after SHP (SUSTAIN HAND GRIP TEST) significantly decreased in breast cancer patients after chemotherapy treatment.

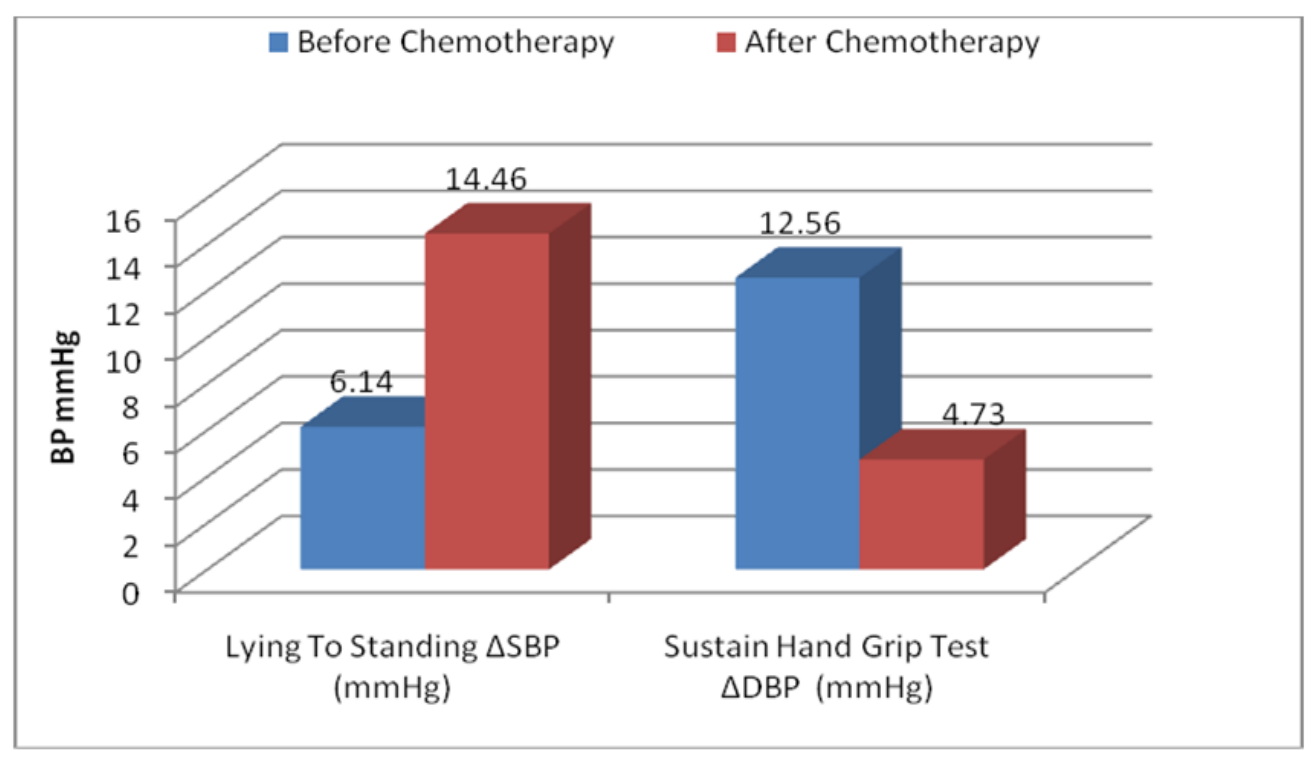

\section{DisCUSSION}

The control of cardiovascular system via autonomic nervous system (ANS) varies from one individual to another and is also affected by many diseases and there treatment. Anthracycline chemotherapy affecting any level of neural axis can impact on ANS and causes symptoms of autonomic dysfunctions. Cardiovascular autonomic neuropathy is a common form of autonomic neuropathy, causing abnormalities in heart rate and central and peripheral vascular dynamics. As the heart and great vessels received significant amount of autonomic innervations, so dysfunction of some portion of ANS can affect cardiovascular control. Therefore cardiovascular reflex test has been most widely used as they are non-invasive, results are easy to produce and they reflect the state of ANS throughout the body.

\section{Sympathetic Activity}

(i) Blood pressure response to standing Basal blood pressure was taken with the patient lying down quietly. The patient was asked to standup and a second reading was taken. A difference of systolic blood pressure (SBP) more than $30 \mathrm{mmHg}$ between the standing and lying blood pressure was considered positive for autonomic neuropathy.

(ii) Blood pressure response to sustained handgrip the patient was asked to perform sustained handgrip for one minute. At the end of one minute blood pressure was recorded. An increase in diastolic blood pressure (DBP) of less than $15 \mathrm{mmHg}$ was considered positive.

\section{Pesent Study}

\begin{tabular}{|c|c|c|c|}
\hline Sympathetic Test & Before Treatment & After Treatment & P- Value \\
\hline$\Delta$ SBP $(\mathbf{m m H g})$ & $6.14 \pm 6.102$ & $14.46 \pm 8.04$ & $0.002 \mathbf{S}$ \\
\hline$\Delta$ DBP (mmHg) & $12.56 \pm 3.51$ & $4.73 \pm 2.55$ & $0.004 \mathbf{S}$ \\
\hline
\end{tabular}


In the present study there is a fall in systolic blood pressure increases and statistically significant $(\mathrm{P}=0.002)$ in breast cancer patients after chemotherapy treatment. In breast cancer patients during sustained hand grip, a sharp decrease in diastolic blood pressure and statistically significant $(\mathrm{P}=.004)$ in breast cancer patients after chemotherapy occurred due to heart rate dependent increased in cardiac output with unchanged peripheral vascular resistance, however in breast cancer patients (After chemotherapy treatment) with autonomic damage the raised in blood pressure was abnormally small. In response to contraction of muscles that activate small fibres in the afferent arm of the reflex arc the heart rate rise due to decreased parasympathetic activity, however in breast cancer patients (After chemotherapy treatment) the rise is very small. According to duration diastolic blood pressure statistically significant $(\mathrm{P}=.004)$ and more decrease with increases the duration of treatment.

Similar studies observed by Maria Viniegra a, Marcelo Marchetti et al. they pragmatic chemotherapy with anthracycline is associated with a significantly higher percentage of abnormal tests for cardiovascular function. Abnormal variations in heart rate on standing and in diastolic blood pressure during handgrip.

Viniegra M, Marchetti conducted autonomic function test in anthracycline treated patients. Chemotherapy with anthracycline is associated with a significantly higher percentage of abnormal tests for cardiovascular autonomic functions [7].

Ekholm $\mathrm{E}$ found heart rate responses to the autonomic function tests did not changes after docetaxel treatments the blood pressure response to standing was enhanced and systolic blood pressure variability decreased after three or four cycles of docetaxel [8].

\section{CONCLUSION}

$\triangle \mathrm{SBP}(\mathrm{mmHg})$ after Standing was significantly increased $(\mathrm{P}<0.002)$ In breast cancer patients after chemotherapy treatment $(14.46 \pm 8.04 \mathrm{mmHg})$ as compared to before chemotherapy treatment in breast cancer patients $(6.14 \pm 6.10 \mathrm{mmHg})$. Sustain handgrip test (SHP) rise $\triangle \mathrm{DBP}(\mathrm{mmHg})$ was significantly (P $<0.0004)$ altered in breast cancer patients after chemotherapy (Anthracycline group of drug) treatment $(4.73 \pm 2.55)$ as compared to before treatment in breast cancer patients $(12.56 \pm 3.51)$.

\section{REFERENCES}

1. http://www.cancer.gov/cancertopics/what-is-cancer National Cancer Institute. US. National Institute of Health.

2. Parkin DM. International variation. Oncogene. 2004 Aug; 23(38):6329-40.

3. Anthracycline from Wikipedia the free encyclopedia. Steinherz LJ, Steinherz PG, Tan C. Cardiac failure and dysrhythmias 6-19 years after anthracycline therapy: a series of 15 patients. Medical and pediatric oncology. 1995 Jun;24(6):352-61.

4. Levy MN. Brief reviews: sympathetic-parasympathetic interactions in the heart. Circulation research. 1971 Nov;29(5):437-45

5. Shaaban AM, Sloane JP, West CR, Moore FR, Jarvis C, Williams EM, Foster CS (2002). Histopathologic types of benign breast lesions and risk of breast cancer. Am J Surg Pathol 26: 421-430.

6. Viniegra M, Marchetti M, Losso M, Navigante A, Litovska S, Senderowicz A. Cardiovascular autonomic function in anthracycline-treated breast cancer patients. Cancer Chemother Pharmacol. 1990;26(3):227-31.Research article

7. Guo Y, Palmer JL, Strasser F, Yusuf SW, Bruera E. Heart rate variability as a measure of autonomic dysfunction in men with advanced cancer. European journal of cancer care. 2013 Sep;22(5):612-6. 